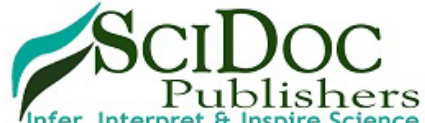

\author{
International Journal of Dentistry and Oral Science (IJDOS) \\ ISSN: 2377-8075
}

\title{
Association of Age and Gender of Patients Who Underwent Class I Amalgam Restoration in Maxillary First Molars - A Retrospective Analysis
}

Research Article

\author{
Swarna SK ${ }^{1}$, Delphine Priscilla Antony $\mathrm{S}^{2}$, Haripriya S
}

${ }^{2}$ Senior Lecturer, Department of Conservative, Dentistry and Endodontics, Saveetha Dental College and Hospitals, Saveetha Institute of Medical and Technical Sciences(SIMATS), Saveetha University, Chennai 600 077, Tamil Nadu, India.

${ }^{1}$ Post Graduate Student, Department of Conservative, Dentistry and Endodontics, Saveetha Dental College and Hospitals, Saveetha Institute of Medical And Technical Sciences (SIMATS), Saveetha University, Chennai 600 077, Tamil Nadu, India.

\section{Abstract}

Amalgam is an alloy of silver, copper, tin and zinc combined with mercury. It has been used as restorative material for more than 150 years. It can be used in individuals of all ages in stress bearing areas where esthetics is not a concern. This aim of the study was to derive an association between age, gender of patients who underwent class I amalgam restorations in maxillary first molars in the South Indian population. A total of 83 case sheets of patients who had undergone class I amalgam restoration in maxillary first molar were reviewed and analyzed statistically for association with age and gender. The patients selected for the study were in the age group of 18-65 years of age. Data was tabulated using excel sheets. The association of age and gender in patients choosing class I amalgam restoration as treatment option, was evaluated statistically using SPSS software. The people included in the study were in the age group of $18-65$ years. 56 out of 83 patients $(67.4 \%)$ were in $18-30$ years of age. But there was no significant association between age and the treatment procedure $(\mathrm{p}$ value $=0.805)$. Out of 83 teeth, $48(57.8 \%)$ were male and $35(42.1 \%)$ were female patients. There was no significant association between gender and class I amalgam restoration, $p$ value $=0.532(p>0.05)$. Within the limitations of the study, there was no significant association between age, gender with class I amalgam restoration.

Keywords: Amalgam; Amalgam Restoration; Class I Cavity; Dental Amalgam; Maxillary First Molar.

\section{Introduction}

Amalgam is an alloy of silver, copper, tin and zinc combined with mercury. Unreacted alloy particles of silver-tin are considered as gamma phase [1]. These particles combine with mercury and form a matrix consisting of gamma $1\left(\mathrm{Ag}_{2} \mathrm{Hg}_{3}\right)$ and gamma $2(\mathrm{Sn} 7-8 \mathrm{Hg})$. The gamma-2 phase is the weakest phase of amalgam and gives rise to a porous and weak amalgam matrix. Copper added to gamma 2 phase, replaces tin mercury phase with $\left(\mathrm{Cu}_{5}\right.$ $\mathrm{Sn}_{5}$ ) copper tin phase.

Louis Regnart is known as Father of Amalgam. In 1959, Dr. Wilmer Eames [2] developed a low mercury technique to alloy mixing ratio that dropped from 8:5 to 1:1. Modern amalgams use proportioned alloy consisting of $42 \%$ to $45 \%$ mercury by weight as well as calcium fluoride compositions [3].
In 1943, the American Society of Dental Surgeon (ASDA) declared amalgam to be malpractice due to mercury poisoning which was the beginning of amalgam war [4]. In 1958, American Dental Association (ADA) did not forbid amalgam usage [5]. In 1991, National Institute of Health-National Institute for Dental Research (NIH-NIDR) and FDA concluded that amalgam did not cause any significant health hazard [6].

Due to its metallic color, most clinicians and patients preferred tooth colored filling materials. Nevertheless, amalgam has numerous advantages over composites such as low cost, ease of application, strength, durability and bacteriostatic effects [7].

Tooth colored restorations with superior properties have greatly reduced the usage of amalgam as posterior restorative material.

*Corresponding Author:

Delphine Priscilla Antony. S,

Senior Lecturer, Department of Conservative, Dentistry and Endodontics, Saveetha Dental College and Hospitals, Saveetha Institute of Medical and Technical Sciences(SIMATS), Saveetha University, Chennai 600 077, Tamil Nadu, India.

E-mail: delphine.sdc@saveetha.com

Received: October 30, 2019

Accepted: November 28, 2019

Published: November 30, 2019

Citation: Swarna SK, Delphine Priscilla Antony S, Haripriya S. Association of Age and Gender of Patients Who Underwent Class I Amalgam Restoration in Maxillary First Molars - A Retrospective Analysis. Int J Dentistry Oral Sci. 2019;S2:02:002:5-9. doi: http://dx.doi.org/10.19070/2377-8075-SI02-02002

Copyright: Delphine Priscilla Antony. $\mathbf{S}^{\odot} 2019$. This is an open-access article distributed under the terms of the Creative Commons Attribution License, which permits unrestricted use, distribution and reproduction in any medium, provided the original author and source are credited. 
Nevertheless, the strength, longevity, ease of application in difficult isolation areas, still supports the usage of amalgam in dentistry. This aim of this study was to derive an association between Age, Gender of patients who underwent Class I Amalgam restorations in Maxillary first molars in the South Indian population.

\section{Materials And Methods}

This comparative Retrospective analytical study was conducted at Saveetha Dental College in 2020. Case sheets from 1st June 2018 to $31 \mathrm{st}$ March 2019 were reviewed and analyzed. A total of 86,000 patient case sheets were screened and 83 case sheets of patients undergoing class I amalgam restoration for maxillary first molars were reviewed, evaluated and analyzed. The case sheets were cross-verified by another examiner to avoid missing any data. The age, gender, tooth number were checked by data evaluation and photographs. The patients included in the study were in the age group of 18-65 years. Both right and left maxillary molars with class I amalgam restorations were included in the study.

Sampling bias was minimized by verifying photographs of patients and restoration. Incomplete data was verified from concerned patient case sheets/department. Gross incomplete date case sheets were excluded as it affects the study. The data were tabulated in Excel sheets.

\section{Statistical Analysis}

Statistical analysis was done using SPSS software. The independent variables assigned as age and gender and dependent variable were maxillary right and left first molars treated with class I amalgam restoration. The statistical test that was used to check significance of association was the Chi square test. The type of analysis performed was associative and descriptive using SPSS software (SPSS) version 21.0, SPSS, Chicago, IL, USA). $\mathrm{p}$ value less than 0.05 would be considered as a significant value statistically.

\section{Results and Discussion}

The people included in the study were in the age group of 18- 65 years. 56 out of 83 patients $(67.4 \%)$ were in 18-30 years of age, 14 patients $(16.8 \%)$ were in the age group of $31-40$ years, 10 patients $(12 \%)$ were in the age group of $41-50$ years. (Table 1 )(Fig 1). But there was no significant association between age and the treatment procedure, $\mathrm{p}$ value $=.805(\mathrm{p}>0.05)($ Table 2$)$. Out of 83 teeth, $48(57.8 \%)$ were male and $35(42.1 \%)$ were female patients (Table 3)(Fig 2). There was no statistically significant difference between gender and class I amalgam restoration (Table 4). The frequency of maxillary right and left maxillary first molars treated with class I amalgam restoration was analyzed (Fig 3)

The low copper amalgams (before 1963) had a limited life span

Table 1. Distribution of Class I amalgam restoration in maxillary first molar among the different age groups. Out of 83 patients, 56 patients $(67.4 \%)$ were in the age group of $18-30$ years, 14 patients $(16.8 \%)$ were in the age group of $31-40$ years, 10 patients $(12 \%)$ were in the age group of $41-50$ years and 3 patients $(3.6 \%)$ were above 50 years of age.

\begin{tabular}{|c|c|c|c|c|}
\hline Age & Maxillary right first molar & Maxillary left first molar & Frequency & Percentage \\
\hline 18-30 years & 29 & 27 & 56 & $67.40 \%$ \\
\hline 31- 40 years & 9 & 5 & 14 & $16.80 \%$ \\
\hline $41-50$ years & 6 & 4 & 10 & $12 \%$ \\
\hline$>50$ years & 2 & 1 & 3 & $3.60 \%$ \\
\hline Total & 46 & 37 & 83 & $100 \%$ \\
\hline
\end{tabular}

Table 2. Shows association between age and class I Amalgam restoration. Shows the results of Chi square test indicating association between Age and Class I Amalgam restoration. According to Chi square test, $p$ value $=0.805$. $(p>0.05)-$ statistically not significant.

\begin{tabular}{|c|c|c|c|}
\hline & Value & df & $\begin{array}{c}\text { Asymptomatic } \\
\text { Significance } \\
\text { (2- sided) }\end{array}$ \\
\hline Pearson Chi- square & 0.983 & 3 & 0.805 \\
\hline Likelihood ratio & 0.995 & 3 & 0.802 \\
\hline Linear- by- linear Association & 0.684 & 1 & 0.408 \\
\hline No of valid cases & 83 & & \\
\hline
\end{tabular}

Table 3. Distribution of Class I Amalgam restoration in Maxillary first molar amongst Gender. Out of 83 patients, 48 patients (57.8\%) with class I Amalgam restoration in maxillary first molars were male and 35 patients(42.1\%) were female.

\begin{tabular}{|c|c|c|c|c|}
\hline Gender & Maxillary right first molar & Maxillary left first molar & Frequency & percentage \\
\hline Male & 28 & 20 & 48 & $57.80 \%$ \\
\hline Female & 18 & 17 & 35 & $42.10 \%$ \\
\hline Total & 46 & 37 & 83 & $100 \%$ \\
\hline
\end{tabular}


Table 4. Association between Gender and Class I amalgam restoration in maxillary first molar. Table 4 shows the results of Chi square test indicating the association between Gender and Class I Amalgam restoration. According to Chi square test, $\mathrm{p}$ value $=0.532(\mathrm{p}>0.05)-$ statistically not significant .

\begin{tabular}{|c|c|c|c|c|c|}
\hline & Value & df & $\begin{array}{c}\text { Asymptomatic Signifi- } \\
\text { cance ( 2- sided) }\end{array}$ & $\begin{array}{c}\text { Exact Sig. } \\
\text { (2- sided) }\end{array}$ & $\begin{array}{c}\text { Exact Sig. } \\
\text { (1- sided) }\end{array}$ \\
\hline Pearson Chi- square & 0.391 & 1 & 0.532 & & \\
\hline Continuity correction & 0.161 & 1 & 0.688 & & \\
\hline Likelihood ratio & 0.39 & 1 & 0.532 & & 0.344 \\
\hline Fisher's exact test & & & & 0.655 & \\
\hline Linear- by- linear Association & 0.386 & 1 & 0.534 & & \\
\hline N of Valid cases & 83 & & & & \\
\hline
\end{tabular}

Figure 1. Association between age and class I amalgam restoration. Shows the Bar chart indicating the association between age of patient and class $I$ amalgam restoration. $X$ axis represents the age of patient and $Y$ axis represents the number of class $I$ amalgam restoration done in maxillary first molar. Maxillary right 1st molar (Blue) and Maxillary left 1st molar (Red).The patients in the age group of 1830 years frequently underwent class I Amalgam restoration in maxillary first molar. According to Chi square test, $\mathrm{p}$ value $=.805$, showed no statistically significant difference $(\mathrm{p}>0.05)$. There was no association between age and class I Amalgam restoration in maxillary first molar.

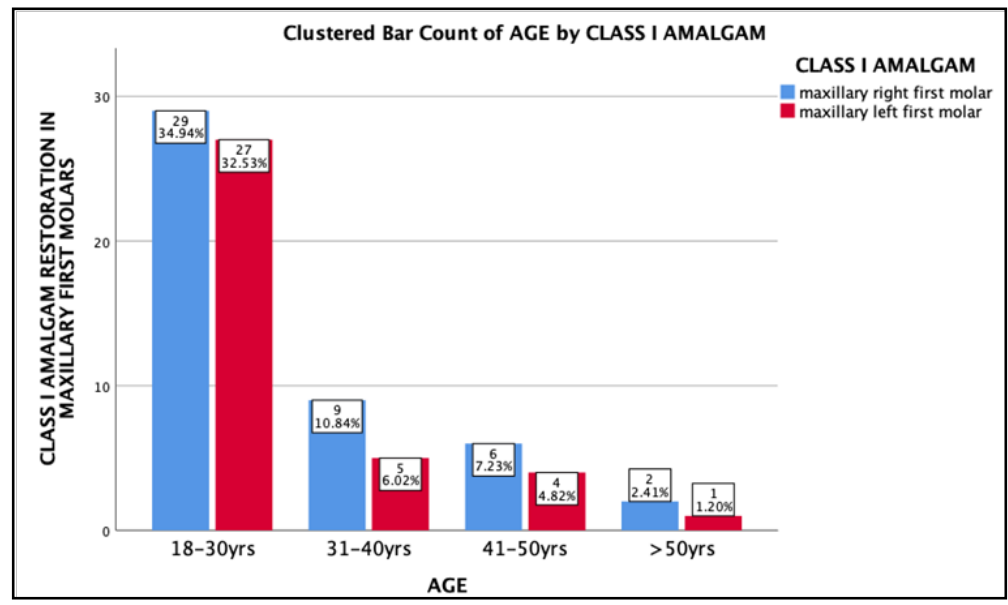

Figure 2. Bar chart indicating the association between Gender of patient and class I amalgam restoration. $\mathrm{X}$ axis represents the gender of the patient, $\mathrm{Y}$ axis represents the number of class $\mathrm{I}$ amalgam restoration done in the maxillary first molar.Maxillary right 1st molar (Blue) were more common in male patients when compared to Maxillary left $1 \mathrm{st}$ molar (Red).According to Chi square test, $\mathrm{p}$ value $=$ 0.532 , showed no statistically significant difference $(\mathrm{p}>0.05)$. There was no association between Gender and class I Amalgam restoration in maxillary molar.

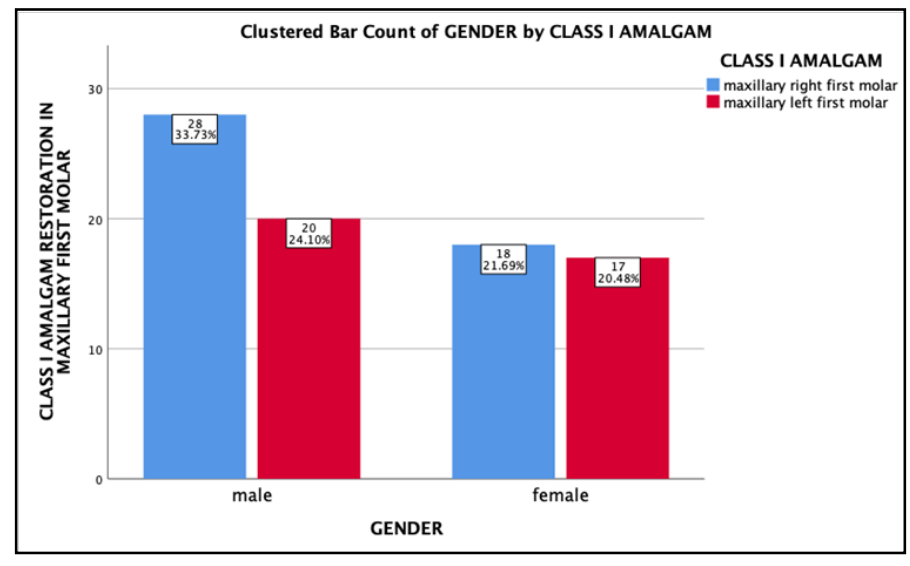

due to gamma-2 phase, which resulted in corrosion thus weakening the restoration. But the high copper amalgam has studies proving satisfactory performance for over 12 years [8, 9] Letzel et al investigated survival and modes of failure of amalgam restorations in class I and class II lesions during follow up periods of 30 to 84 months [10]. The fracture pattern most commonly observed in amalgam restorations was bulk fracture (4.6\%) followed by tooth fracture $(1.9 \%)$ and marginal ridge fracture $(1.3 \%)$. But only $0.8 \%$ of amalgam restorations failed [11].

Manhart et al, stated that the principal reason for failure of amalgam were secondary caries, fracture, marginal deficiencies, wear and post-operative sensitivity [12]. Various studies have been done to determine association between amalgam restoration and 
Figure 3. Frequency graph representing the tooth number and class I amalgam restoration in maxillary first molars. $\mathrm{X}$ axis represents the tooth number and $\mathrm{Y}$ axis represents the number of class I amalgam restorations done in the maxillary first molar. Out of 83 patients, 46 teeth(55.4\%) were maxillary right first molar and 37 teeth $(44.5 \%)$ were maxillary left first molar. The maximum restorative treatment was done for maxillary right first molar followed by left maxillary first molar.

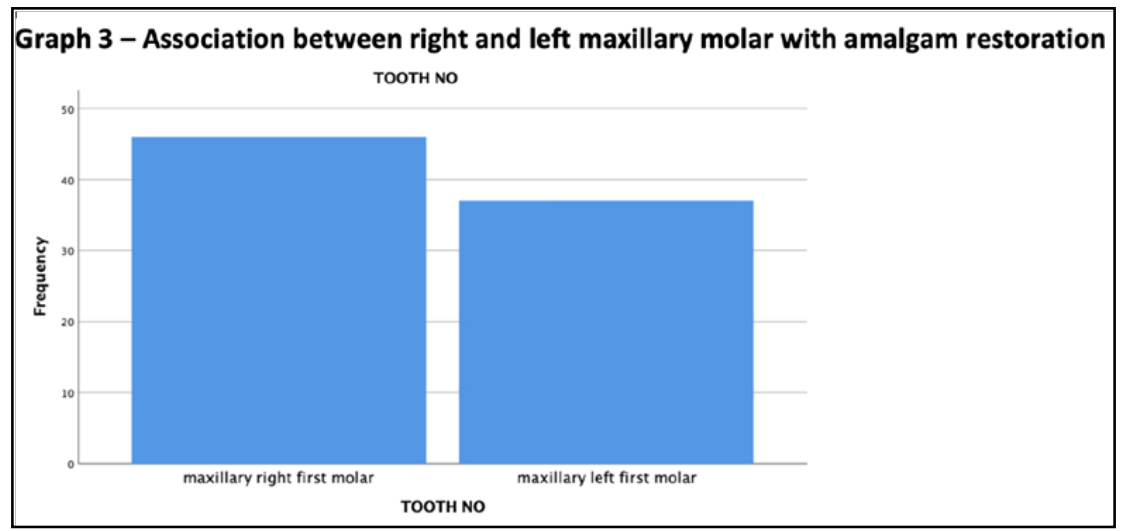

diseases such as Alzheimer's disease [13], Essential tremors [14] and Parkinson's disease [15]. This was the first kind of study to analyze the association between age and gender in patients undergoing class I amalgam restorations in the South Indian population.

Most of the cases in our study were in the age group of 18-30 years. But both gender and age did not have any statistically significant association with class I amalgam restorations. With rising concerns in mercury release from amalgam fillings, there has been confusion among clinicians, whether to still use amalgam as a restorative material. But the strength, durability and survival rates of amalgam restoration are far better than composite or any other tooth coloured filling material, which compels us to still use this restorative material $[16,17]$.

Plasmans et al evaluated long term survival of large multi-surface restorations and found that extension of extensive amalgam restorations (i.e.) number of cases involved in restoration, had no influence on the survival rate, which is in accordance with retrospective study results of Robbins and Summit, who found a 50\% survival rate of 11.5 years [18]. Rathore et al, did an extensive review of the effect of mercury in dental restorations and concluded that there is no evidence of any adverse health effect due to dental amalgam restorations [1].

Composite restorations are highly esthetic but they fail to still totally replace amalgam restorations due to many facts. Hodge et al stated that the overall failure rate of composite restorations in posterior teeth at 8 years was $13.7 \%$ and the failure rate was 2 to 3 times that of control high copper amalgam restorations $(5.8 \%)$. Main modes of failure of composites were bulk fracture and secondary caries which contributed to $72 \%$ of failure rate [19]. Arvind Shenoy has done a critical review comparing amalgam and composite restorations [20]. He concluded that high copper amalgams are superior to composites in large restorations and cusp capping. The composite restorations are more technique sensitive but offer a better seal and meet patient's demands for aesthetics [21]. The limitations of the study include a very small sample size and population which cannot be correlated to a larger population.

Incaseof deep amalgam restorations with secondary caries, root canal treatment has to be done. Various irrigants with antimicro- bial and substantivity have been studied for their interactions and effectiveness [22-24]. Irrigant activation is needed for effective disinfection of the root canal system [25]. The infected and inflamed pulp should be completely removed to achieve success in root canal treatment $[26,27]$. The root canal treatment for amalgam restored teeth should be taken extra care during cleaning and shaping procedures. Care should be taken to maintain remaining dentin thickness as much as possible [28, 29], . Also incase of deep amalgam restorations, the base or the restoration itself, might act as a mild irritant, thus causing the canals to calcify eventually, thereby further making the root canal treatment difficult [30].

Due to traumatic injuries, the tooth may be fractured [31], luxated or avulsed [32]. The prognosis of teeth depends on nature, time and impact of the injury. The traumatized tooth is never a good candidate for amalgam restoration which has a high compressive strength. The treatment plan should always follow reliable pulp vitality tests taken at regular recall appointments [33]. With advancing caries detection methods and minimal intervention techniques [34] the caries can be diagnosed and treated at the earliest. White spot lesions can be treated by remineralizing agents and bioactive agents that restore the calcium phosphate balance, thus favoring the remineralization phase $[35,36]$.

The limitations of the study is the small sample size which cannot be generalized to a large population. Further studies can be done with large retrospective data collection and analysis to understand the extent of usage of amalgam in dentistry and its significant association with age and gender.

\section{Conclusion}

Within the limitations of the study, there was no significant association between age, gender and tooth number in relation to class I amalgam restorations in maxillary first molars. Although the amalgam restorations are unaesthetic and have concerns regarding mercury toxicity, it is still being used as a restorative material due to its strength, longevity and simplicity of procedure.

\section{Acknowledgement}

The authors would like to acknowledge all the faculty of the De- 
partment of Conservative Dentistry and Endodontics, Saveetha Dental College, Chennai for their help with data collection for this study.

\section{References}

[1]. Rathore M, Singh A, Pant VA. The dental amalgam toxicity fear: a myth or actuality. Toxicology international. 2012 May;19(2):81.

[2]. EAMES WB. Preparation and condensation of amalgam with a low mercuryalloy ratio. J Am Dent Assoc. 1959 Apr;58(4):78-83.Pubmed PMID: 13640864.

[3]. Innes DB, Youdelis WV. Calcium fluoride in amalgam for caries prevention. J Dent Res. 1966 Jan-Feb;45(1):94-8.Pubmed PMID: 5216802.

[4]. Harris CA. The American Journal of Dental Science, 1845-6, Published Under the Auspices of the American Society of Dental Surgeons (Classic Reprint), Forgotten Books.2017; 6: 350.

[5]. Molin C. Amalgam-fact and fiction. Eur J Oral Sci. 1992 Feb;100(1):66-73.

[6]. Reese JA. Introduction to the Nih Technology Assessment Conference on Effects and Side-Effects of Dental Restorative Materials. ADR.1992;6:3.

[7]. Berry TG, Summitt JB, Chung AK, Osborne JW. Amalgam at the new millennium. JADA. 1998 Nov 1;129(11):1547-56.

[8]. Osborne JW, Norman RD. 13-year clinical assessment of 10 amalgam alloys. Dent Mater. 1990 Jul;6(3):189-94.Pubmed PMID: 2086293.

[9]. Moraschini V, Fai CK, Alto RM, Dos Santos GO. Amalgam and resin composite longevity of posterior restorations: A systematic review and meta-analysis. J Dent. 2015 Sep;43(9):1043-1050.Pubmed PMID: 26116767.

[10]. Guthrow CE, Johnson LB, Lawless KR. Corrosion of dental amalgam and its component phases. J Dent Res. 1967 Nov-Dec;46(6):1372-81.Pubmed PMID: 5234907.

[11]. Letzel H, Van't Hof MA, Vrijhoef MM, Marshall Jr GW, Marshall SJ. Controlled clinical study of amalgam restorations: survival, failures, and causes of failure. Dent Mater. 1989 Mar 1;5(2):115-21.

[12]. Manhart J, Neuerer P, Scheibenbogen-Fuchsbrunner A, Hickel R. Three-year clinical evaluation of direct and indirect composite restorations in posterior teeth. J Prosthet Dent. 2000 Sep;84(3):289-96.Pubmed PMID: 11005901.

[13]. Sun YH, Nfor ON, Huang JY, Liaw YP. Association between dental amalgam fillings and Alzheimer's disease: a population-based cross-sectional study in Taiwan. Alzheimers Res Ther. 2015 Nov 12;7(1).Pubmed PMID: 26560125.

[14]. Tseng CF, Chen KH, Yu HC, Chang YC. Association between Dental Amalgam Filling and Essential Tremor: A Nationwide Population-Based Case Control Study in Taiwan. Int J Environ Res Public Health. 2020 Jan 27;17(3):780.Pubmed PMID: 32012693.

[15]. Hsu YC, Chang CW, Lee HL, Chuang CC, Chiu HC, Li WY, et al. Association between History of Dental Amalgam Fillings and Risk of Parkinson's Disease: A Population-Based Retrospective Cohort Study in Taiwan. PLoS One. 2016 Dec 1;11(12):e0166552.Pubmed PMID: 27906991

[16]. Bonsor SJ, Chadwick RG. Longevity of conventional and bonded (sealed) amalgam restorations in a private general dental practice. Br Dent J. 2009 Jan 24:206(2):E3.Pubmed PMID: 19148188.

[17]. Kermanshah H, Ghabraei S, Kharrazifard MJ, Monjazeb M, Farahmandpour N. Longevity of Amalgam Build-Up Restorations in Endodontically Treated Teeth. JIDAI. 2018 Oct 10;30(4):132-8.

[18]. Plasmans PJ, Creugers NH, Mulder J. Long-term survival of extensive amal- gam restorations. J. Dent. Res. 1998 Mar;77(3):453-60.

[19]. Collins CJ, Bryant RW, Hodge KL. A clinical evaluation of posterior composite resin restorations: 8-year findings. J Dent. 1998 May;26(4):311-7. Pubmed PMID: 9611936.

[20]. Shenoy A. Is it the end of the road for dental amalgam? A critical review. J Conserv Dent. 2008 Jul;11(3):99-107. doi: 10.4103/0972-0707.45247. Pubmed PMID: 20142895.

[21]. Hussainy SN, Nasim I, Thomas T, Ranjan M. Clinical performance of resinmodified glass ionomer cement, flowable composite, and polyacid-modified resin composite in noncarious cervical lesions: One-year follow-up. JCD. 2018 Sep;21(5):510.

[22]. Noor S. Chlorhexidine: Its properties and effects.RJPT. 2016;9(10):1755.

[23]. Siddique R, Jayalakshmi S. Assessment of Precipitate Formation on Interaction of Chlorhexidine with Sodium Hypochlorite, Neem, Aloevera and Garlic: An in vitro Study. Indian J. Public Health. 2019 Nov 1;10(11):3648.

[24]. Siddique R, Sureshbabu NM, Somasundaram J, Jacob B, Selvam D. Qualitative and quantitative analysis of precipitate formation following interaction of chlorhexidine with sodium hypochlorite, neem, and tulsi. J Conserv Dent. 2019 Jan;22(1):40-47.Pubmed PMID: 30820081.

[25]. Ramamoorthi S, Nivedhitha MS, Divyanand MJ. Comparative evaluation of postoperative pain after using endodontic needle and EndoActivator during root canal irrigation: A randomised controlled trial. Aust Endod J. 2015 Aug;41(2):78-87.Pubmed PMID: 25195661.

[26]. Teja KV, Ramesh S, Priya V. Regulation of matrix metalloproteinase-3 gene expression in inflammation: A molecular study. JCD. 2018 Nov;21(6):592.

[27]. Manohar MP, Sharma S. A survey of the knowledge, attitude, and awareness about the principal choice of intracanal medicaments among the general dental practitioners and nonendodontic specialists. Indian J Dent Res. 2018 Nov 1;29(6):716.

[28]. Ramanathan S, Solete P. Cone-beam Computed Tomography Evaluation of Root Canal Preparation using Various Rotary Instruments: An in vitro Study. JCDP. 2015 Nov 1;16(11):869-72.

[29]. Teja KV, Ramesh S. Shape optimal and clean more.SEJ. 2019 Sep 1;9(3):235.

[30]. Kumar D, Antony S. Calcified Canal and Negotiation-A Review.RJPT. 2018;11(8):3727.

[31]. Jose J, Subbaiyan H. Different Treatment Modalities followed by Dental Practitioners for Ellis Class 2 Fracture-A Questionnaire-based Survey. Open Dent. J. 2020 Feb 18;14(1):59-65.

[32]. Rajakeerthi R, Ms N. Natural Product as the Storage medium for an avulsed tooth-A Systematic Review. Cumhur. Dent. J.. 2019;22(2):249-56.

[33]. Janani K, Palanivelu A, Sandhya R. Diagnostic accuracy of dental pulse oximeter with customized sensor holder, thermal test and electric pulp test for the evaluation of pulp vitality: an in vivo study. Braz. Dent. Sci. 2020 Jan $31 ; 23(1)$.

[34]. Ravinthar K. Recent advancements in laminates and veneers in dentistry. RJPT. 2018;11(2):785.

[35]. Nandakumar M, Nasim I. Comparative evaluation of grape seed and cranberry extracts in preventing enamel erosion: An optical emission spectrometric analysis. J Conserv Dent. 2018 Sep-Oct;21(5):516.Pubmed PMID: 30294113.

[36]. Rajendran R, Kunjusankaran RN, Sandhya R, Anilkumar A, Santhosh R, Patil SR. Comparative Evaluation of Remineralizing Potential of a Paste Containing Bioactive Glass and a Topical Cream Containing Casein Phosphopeptide-Amorphous Calcium Phosphate: An in Vitro Study.PBOCI. 2019;19:1-10 